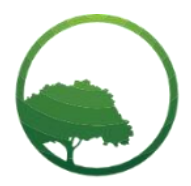

Research in Business \& Social Science

IJRBS VOL 10 NO 3 ISSN: 2147-4478

\title{
Covid-19 financial distancing for MSMEs in Kenya
}

\author{
Nathan Mwenda Mutwiri
}

Kenyatta University, School of Business, Nairobi, Kenya

\author{
A R T I C LE INFO \\ Article history: \\ Received 02 March 2021 \\ Received in rev. form 13 April 2021 \\ Accepted 15 April 2021 \\ Keywords: \\ Covid 19, Pandemic, Financial \\ Distancing, MSMEs, Kenya \\ JEL Classification: \\ B27
}

\begin{abstract}
A B S T R A C T
The Micro Small and Medium Enterprises (MSMEs) are important for every nation's economic development. They provide employment and spur the growth of multiple sectors in the economy. The Covid-19 pandemic has negatively affected MSMEs' performance. The study seeks to demonstrate why COVID 19 may lead to the terminal quarantining of MSMEs. The study is anchored on decision usefulness and information asymmetry theories. The study adopted a descriptive research methodology and sampled MSMEs within Nairobi City County. The study used SPSS to analyze data in addition to Microsoft excel. The study found that over 70\% of MSMEs had their sales decline by over 65\% while 95\% of them had their sales decline by over 30\%. The study found that about 68\% of MSMEs lacked financial management skills. The study recommends that with legal and institutional reforms, the government needs to develop a financing framework for MSMEs.
\end{abstract}

(C) 2021 by the authors. Licensee SSBFNET, Istanbul, Turkey. This article is an open access article distributed under the terms and conditions of the Creative Commons Attribution (CC BY) license (http://creativecommons.org/licenses/by/4.0/).

\section{Introduction}

The Micro, Small and Medium Enterprise (MSMEs) play a crucial role in the development of economy. They provide the muchneeded employment, economic and social transformation I Kenya. (KNBS, 2016). Asper the Kenya National Bureau of statistics survey in 2016, the number of persons engaged by MSME was approximately 15 million, with Micro sized enterprises accounting for $81.1 \%$ of the employment reported in MSMES. MSMEs contribute $98 \%$ of all business in Kenya and contribute to about $40 \%$ of the GDP (KNBs, 2016).

Promotion of dynamic and enabling operating environment for small and MSMEs is seen as apriority in most economies, this is both in emerging as well-developed economies. (Nunoo \& Andoh, 2012).SMES play a primary driver for job creation and GDP growth. They contribute enormously to economic diversification and social stability. Despite the crucial role of the MSMES, they still face a myriad of challenges. Viffa Consult, (2018) showed that access to financing, access to markets, legal and administrative challenges were among the many challenged faced by MSMES. In the pre COVID-19 period MSMES in Kenya faced a great challenge of financing their operations. The mainstream banks avoided lending to this critical sector of the economy. Beck \& Demigurc, (2006) explained that SMEs are more credit constrained than large firms, affecting their growth and possibilities to innovate. This despite SMES being the Heartbeat of a vibrant private sector and Key. Kenya Treasury, (2011) acknowledged that Increasing access to financial services for MSMEs is a key pillar to ensure a comprehensive Financial Sector Reform and Development strategy (Central Bank of Kenya;The world Bank,FSD Kenya, 2015). The sector needs multi sectoral support to enable SMES navigate the present crisis. Osano \& Languitone (2016) found that small business support services should be provided to SMES to improve access to finance. Beck (2007) conclude that the weaknesses in financial and legal systems in the developing countries presents a big obstacle in accessing financial products by the SMEs

Whereas MSMEs play a big role in the progression of the economy in Kenya. Most of the close down within the first year of operation. This is no doubt financial constraints (Beck T. , 2007) prevents them from attain their full potential therefore slowing the country from achieving the Vision 2030 goals of a middle class economy. The Covid-19 pandemic has negatively affected MSMEs potential

\footnotetext{
* Corresponding author. ORCID ID: 0000-0002-9158-320X

(C) 2021 by the authors. Hosting by SSBFNET. Peer review under responsibility of Center for Strategic Studies in Business and Finance. https://doi.org/10.20525/ijrbs.v10i3.1110
} 
to access the much-needed financial services. In addition, the pandemic has negatively affected the performance of MSMES. Sound financial practices and financial literacy is very important in ensuring that the MSMEs are able to bounce back after the epidemic. This study aimed at establishing the magnitude of Financial effects of COVID 19, as well how sound financial management practices and the effects of COVID 19 accessing the literacy of MSMES. The success or failure of the small and medium enterprises is mainly contingent on their financial viability. Most MSMEs problem is the ability to secure sufficient cash flows and working capital to remain afloat and profitable (Chepngetich, 2016).Financial literacy has been shown as an essential in improving the transparency and efficiency of the SMEs and this has a bearing on the ability to achieve organizations objectives. Koitaba (2013) found that Financial illiteracy among the owners and employees of the SMEs is a key shortfall in ensuring that the SMEs are able to manage their operations and cashflows. This lack of prudent management has led to collapse of many SMEs because they are often unable to meet the day to day obligations of their businesses. Usama \& Yusoff (2019) explained that financial literature has an effect of performance of small and medium enterprises in Nigeria.

Accounting and record keeping is a nightmare to many business owners (Alufemi \& Olademeji, 2019). Keeping records of business transactions helps a business owner to keep track of the progress of a business. Dawuda \& Azeko (2015) noted that poor record keeping or non-availability of financial record have consequences of mismanagement of resources and poor cash management. The study also noted that lack of relevant accounting skills and the the cost of hiring professional accounting services was the main hindrance to SMEs keeping proper accounting records. Udoh, (2005) suppoted that most of the SMEs failed because they did not keep proper reocrds and therefore were unable to track their performance. Failure to keep records also meant that they can not proof their kevel of performance in case they seek financial resources in financing institutions.

The objectives of this study were to establish why COVID 19 may lead to terminal quarantining of MSMEs because of lack of lack of financial access. Specifically, the study accessed the impact of COVID 19 on the MSMEs access of Finance, evaluated impact of the of COVID-19 on the performance of MSMES, determined the Impact of sound financial management on MSMEs during the pandemic and finally accessed the financial literacy of MSMES and their adaptability

\section{Literature Review}

\section{Theoretical Background}

\section{Decision Usefulness Theory}

This theory was promoted by scholar George Staubus. Staubus (2000) explained that when the conditions are not ideal, the concept of perfect or true and fair view of financial statement may mean little. In such situations, accountants try to prepare statements or records that are useful to users. For accountants to effectively do this, they need to identify who are the users of the information and understand their decision problems. For instance, creditors need to MSMEs accounting records is to be able to determine whether to advance credit, if they should advance credit then be able to determine how much to advance. Creditors need to evaluate if the mount will be paid in due periods. On the other hand, the Governments may need the information to determine the national effects of epidemics, for instance the current COVID-19 effects on the business operations and economy. The government need information so as to factually determine the interventions to make. Dandago \& Hassan, (2013) opines that financial statements make a tradeoff between relevance and reliability. Both are critical to the quality of financial information, an over emphasis of one will hurt the other. MSMEs need to ensure that information that they generate is adequate and correct so that prudent financial decisions are made. Without useful information, even when firms have financial literacy, good financial management cannot be achieved.

\section{Information asymmetry}

Information asymmetry refers to a situation whereby one party has more information that the other. Asymmetry creates an imbalance of power. Information asymmetry may lead to a moral hazard problem and adverse selection. When Small and medium enterprises fail to keep records by not practicing good financial management, they fail to convince the potential financiers of their credit worthiness. This may make them experience more difficulty in securing financing in these hard times of COVID 19 because they cannot produce records to show proof of their ability to pay.

Financial literacy refers to the financial knowledge and skills that enable a business entrepreneurs or managers to execute effective financial management strategies for the businesses. (Usama \& Yusoff, 2019). Literature is the ability to read and write; knowledge and as well competence is a specific discipline (Atkinson, 2017).

\section{Empirical review}

Dahmen \& Rodriguez, ( 2014) did a research in the United States found that most of the entrepreneurs fall short of the financial skills needed to opearte a business. The study found that most SMEs needed business consultancies services to accelerate their growth. The study found noted that in the 2007- 2009 economc downturn in the united states, The small businesses were the backbone of Americas economy because they suppoted about $46 \%$ of the the gross domestic product (GDP) and provide $49.2 \%$ of private sector employment and up to $99.7 \%$ of the U.S employer firms.

Ropega (2011) found that two major reasons why most small businesses fail based on the Bradley and Moore (2000) include inadequate management skills and poor knowledge of business. Nunoo \& Andoh (2012) found that in Ghana most of the small 
busnieses are excluded from main financial players because they are perceived to be riskier. The study also found most SMES lack the requisite financial literacy and therefore they are unable to utilize even the few available resources.

Financial management practices are key to the success of any business. Rapid changes in the business environment wordwide must transform small and medium enterprises to advance for sustainable developments. Yukun, \& Shagufta (2019) explained that literature has found that $90 \%$ of the SMEs fail in their businesses. The study found that working capital management, financial reporting, accounting information systems and investment decisions an financial practices are associated with positive performance and growth of a firm. Afeef (2011) found that working capital management has an impact on performance. The study found that since most SMEs have as proportion of total assets as working capital, efficient management o working capital has more impact on the performance in SMEs than larger companies.

The empirical studies have results on the effects of the record keeping and the SMES performance. Muchira \& Jagongo (2014) found that the MSES kept a sketch incomplete records, which were poorly and unprofessionally done. The study aslo found that most MSEs did not have accounting systems neither could they afford to hire qualified accountants. The study found that this hindered most businesses form making sound economic decisions. Alufemi \& Olademeji (2019) studied the impact of record keeping on selcted small and medium enterprises in Lagos Metropolis. The study found that whereas owners agreed on the importance of the record keeping, most owners lacked basic skills of accounting.

Amoako, (2013) emphasized the need for recording financial transactions in a business environment. Its only through accurate capturing of information that business can be able to tell whether they are making losses or profits. Moreover, most financial institutions require periodical data on the business operations in order to grant loans and other products.

\section{Research and Methodology}

The study used descriptive research methodology and adopted a positivist philosophy to ensure that the results are objectives and scientific. The study used primary data because it aimed at establishing the impact of the COVID-19 epidemic on the SMEs therefore no available data would be available.

The sample selected for this study depended mostly on the availability of data. Because of the social distancing and work from home measures to contain the spread of the Covid-19, the study used electronic survey through the internet, phone calls interviews for clarification and limited physical questionnaire to avoid contacting the MSMES physically. The total number of registered SMEs in Kasarani Sub county was 839, with most of the Micro enterprises being unregistered. A total population of 120 MSMEs were targeted using convenience sampling method, out of which 84 responded to the study. Normality test was done using Jarque-Bera and the results indicated that the data was normally distributed. The study tested for multicollinearity using the VIF and adopted the rue of the thumb for VIF. All the variable values were within the range of 10 indicating that there was no threat for multicollinearity. The study employed statistical tools for both descriptive and quantitative using SPSS. Research design because the study aimed at accessing the relation and impact of the study variables.

\section{Findings}

The study established that about $58 \%$ of the micro and small enterprises that respondent were owned by men with the balance of $42 \%$ being owned by women. Of the sampled micro and small enterprise only $27 \%$ were owned by the youth i.e owners were of age 35 years and below.

Micro and small enterprises face a major challenge in accessing finance from the financing institutions. This has been caused by several factors. Firstly, the enterprises lack adequate records for their business operations. This makes financial institutions unable to evaluate their capabilities and ability to pay the loans. Lack of records also increases the risk assessment of businesses contributing further to their lack of funds. Most small and micro enterprises rely on personal savings and limited trade credit because most of the main commercial banks are unwilling to lend them.

As a result of little or no savings or trade credit, the business turn to shylocks and digital lenders. These sources of finances are very expensive because they lead to a compounded interest of more than 100\% per annum. The COVID 19 pandemic has worsened their lack of access to trade credit because of the disruptions of trade. The pandemic also instilled a level of uncertainty regarding the going concern of many SMEs, this made even suppliers who loaned them merchandise, to freeze their arrangements. This compounded with the low business operations compounded the already problem of lack of access to finances. 


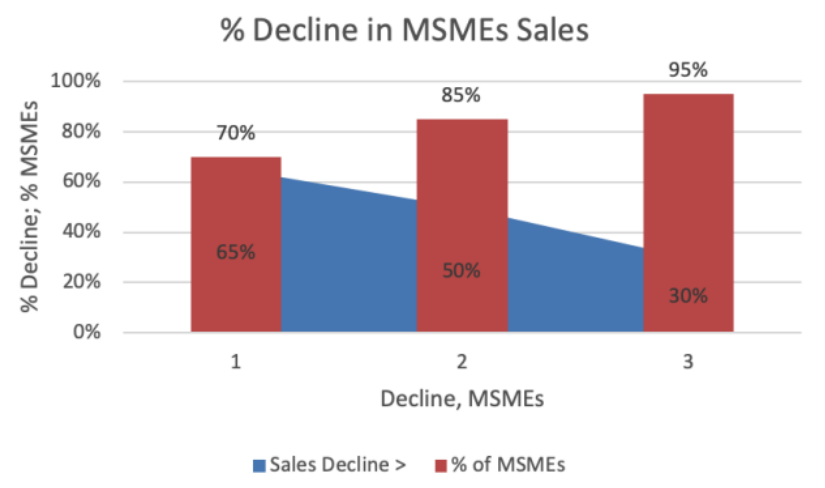

Figure 1: Decline of sales during COVID-19 Period

The figure 1 shows the decline of performance of Micro Small enterprises. Then performance of Micro and Small enterprises has been greatly affected by the COVID-19 pandemic. Whereas, most Small and micro enterprise are not able to prepare complete financial statements such as profit and loss and balance sheet. Their performance was indicated by the level of sales. In the period between March and September 2020, more than 70\% of the sampled enterprises reported a decline of more than $65 \%$ in their revenues. On the other hand, more than more than $95 \%$ of MSMEs had their sales declining by more than $30 \%$. This is enormous dip in their revenues made most of them unable to cover their normal operating expenses. This is because some expenses were fixed regardless of the scale of operation. These expenses included rent and for some enterprise salaries. By the second month a considerable proportion of the small and micro enterprises had to release most of their employees because they could not sustain. In addition, a bulk of these enterprises are facing a serious chance of total collapse. This is because of accumulated expenses which have not been paid. This is despite the fact that since most owners of these enterprises have used all their saving or sales cash generated to meet personal expenses.

The figure 2 below shows the levels of financial records maintenance amongst MSMEs. Financial management is critical for every business enterprise regardless its size. Owners of business enterprises with good skills of financial management skills and who practice them are also able to propel their business to next level of growth. Financial management in small and micro enterprises entails but not limited to having periodic budgets, having financial forecast and planning, cash and working capital management, documentation of all expenses and revenues, maintenance of updated records of cashbook and preparing a simple Profit and loss account. The study established that over $75 \%$ of the sampled enterprises did not maintain a profit and loss account, balance sheet nor prepare budgets for the forthcoming periods. Approximately $40 \%$ prepared a document which may resemble cash book though not as per the required accounting principles and standards. The study established that about $80 \%$ of the enterprises had a way of recording or approximating the sales for the period mostly daily or weekly. However even in these, they did not record each transaction but had a way of netting off cash at the end of the day less to arrive at approximate sales figures. Of concern is that daily cash received for sales is used to offset any purchases of the day or pay any debts the business has therefore not possible to capture an accurate sales value for these enterprises.

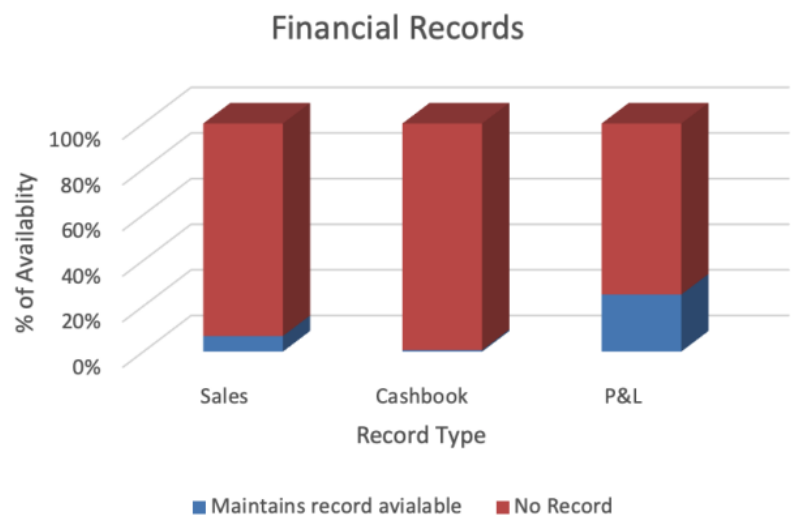

Figure 2: Financial Records Maintenance

Financial literacy refers to the ability of the business owners or managers to carry out financial management functions. These refers to the requisite skills that will be needed to execute day to day business operations relating to finance. Without good financial skills, a business may be curtailed from achieving its full potential. These study found that majority of the small and micro enterprises ( $68 \%$ ) have no little skills on preparation of a simple profit and loss or balance sheet. Most of the enterprises just record the daily net 
sales (after deducting all daily payment). Therefore, with these record it would not be possible to generate proper books of account. The owners of these businesses however have skills of recording payments or receipts when they actually paid in cash. The study established that there is no separation of personal and business expenses. There is so much intertwining between personal injection into the business and personal expenses paid from the daily collections. This is a huge setback in getting the correct position of the business to know whether an enterprise is making profit or loss. It is also difficult to establish he actual capital injected into the business because of drawings from the business as well as the injections into the businesses which are not recorded.

\section{Conclusion}

The study had set out to establish the impact on COVID 19 on the performance of Micro and Small Enterprises, the impact of COVID 19 on the access of finance to small and micro enterprises. The study also sought to establish the effect of sound financial management on performance during Covid and finally access the level of financial literacy of the owners of the micro and small business enterprises. The study found that during the covid-19 period, performance declined by over $60 \%$ for all sampled enterprises. It was also established that though limited financial management, those with better financial management skills were able to navigate the period due to ability to monitor their cash flows. It was established that majority of small and micro enterprises did not keep proper records hence difficult to access their level of capability and risk when applying for financial assistance from commercial institutions. Finally, the study established that majority of the owners or managers of micro and small enterprises do not have requisite financial management skills or rather had low financial literacy.

The study makes the following recommendations based on its findings.

Firstly, Training of Micro and small medium enterprises. There is need for the government to come up with coordinated approaches to training of SMES on financial management and business process. Lack of business skills is a serious challenge in most $\mathrm{f}$ these businesses. This prevents them from attaining their maximum potential within the industries that they work. The government has use the existing institution such as the National industrial Training Authority (NITA) to have a sectoral focused trainings among SMES.

Secondly, the government of Kenya in conjunction with the development partners needs to come with a financing framework for SMES. This would be by establishing a a government owned corporation which will be financed by government and well-wishers and generate a pool to finance the small-scale enterprises based on the sectors they operate. The government can also guarantee the loans that SMES take with other financial institutions also that to ensure that they get more access to financing. By doing this the government will be in a position to ensure that SMES access the finance at an affordable interest rate.

Thirdly, the National government should inject cash to selected sectors within the operations of the MSMES. This would encourage the owners of these entities to invest or concentrate on some selected areas which the government needs more investors and help the governments in its macroeconomic policies. This would further alleviate the problem of capital requirement from Small medium enterprises.

Lastly there is need of legal and institutional reforms. There is a need for SMES friendly laws in regards to set up of businesses, and accessing government and affiliated contracts. Parliament should ensure that there some percentage of all governments tenders that go to SMES. This can be done by having enabling laws which allow SMES to jointly bid to supply to the governments within their areas of operations. This will prevent the current situation where by tender- prenuers obtains lucrative contracts from the governments only for them to outsource the merchandise from Artisans, and MSMES at low prices. In addition there is need to reform the institutions such as the Youth enterprise find, and other government agencies that aid SMES to ensure they ensure that they are serving the interest of SMES.

\section{References}

Afeef, M. (2011). Analyzing the impact of working Capital Management on the profitability of SMEs in Pakistan. International Journal if business and social sciences, 2(22), 173-186.

Alufemi, A., \& Olademeji, J. A. (2019). The Impact of Recordkeeping On the Performance of selected Small and Medium Enterprises in Lagos Metropolis. Journal of Small Business and entrepreneurship Development.7(1), 28-40.

Amoako, G. (2013). Accounting Practices of SMEs; a case study of Kumasi metropolis in Ghana. International Journal of Business and Management 8(24), 73-83.

Atkinson, A. (2017). Financial education for MSMEs and potential Entrepreneurs. Paris: OECD Working Papers on Finance, Insurance, and Private Pensions.

Beck, T. (2007). Financing constraints of SMEs in developing countries. Financing innovation-oriented business to promote entrepreneurship.

Beck, T., \& Demigurc, K. (2006). Small and Medium Enterprises; Access to Financial and Growth Constraint. Journal of Banking and Finance, pp2931-43.

Bradley III, D., \& Moore, H. (2000). Small Business bankruptcy caused by a lack of understanding and consumer needs. ICSB Singapore Conference.

Central Bank of Kenya (2015). The world Bank, FSD Kenya. (2015). Finance Business-Supply; Bank Financing of SMEs in Kenya. FSD Kenya. 
Chepngetich, P. (2016). Effect of Financial literacy and performance SMEs. evidence from Kenya. American Based Research Journal, 26-35.

Dahmen, P., \& Rodriguez, E. (2014). Financial Literacy and Success of Small businesses: An Observation from a small Business Development Center. Numeracy, 7(1)

Dandago, I. K., \& Hassan, N. I. (2013). Decision Usefulness Approach to Financial Reporting: A Case for Malaysian Inland Revenue Board. Asian Economic And Financial Review 3(6), 772-784.

Dawuda, A., \& Azeko, I. (2015). An assessment off financial records-keeping behavior of small-scale business in Ghana;A case study of Bolgatanga Municipality. International Journal of Finance and Accounting 4(3), 187-194.

Kenya Treasury. (2011). Kenya: A Comprehensive financial sector Reform and development strategy.

KNBS. (2016). Micro, Small \& Medium Establishments Basic Report. Kenya National Bureau of Statistics.

Koitaba, E. (2013). Analysis of factors influencing financial control financial literacy in community-based organizations in Baringo County, Kenya. MBA Thesis, Kabarak Public sector in Mirangine Sub-county, Kenya.

Muchira, B. W., \& Jagongo, A. (2014). Record keeping and Growth of Micro and Small Enterprise: An Empirical Study and MSES in Selected Urban Centers in Kenya. Global Journal of Commerce and Management Perspective 3(6), 79-87.

Nunoo, J., \& Andoh, F. (2012). Sustaining Small and Medium Enterprises through Financial service Utilization: Does Financial Literacy Matter? Agricultural \& Applied Economics Association'S 2012 AA Anual Meeting. Seattle, Washington.

Osano, H. M., \& Languitone, H. (2016). Factors Influencing Access to Finance by SMEs in Mozambique: the case of SMEs in Maputo central business district. Journal of Innovation and Entrepreneurship.

Ropega, J. (2011). The Reasons and symptoms of failure in SME. The International Advances in Economics Research, 17(4) :476483.

Staubus, G. J. (2000). The Decision Usefulness Theory of Accounting. Routledge.

Udoh, C. (2005). Causes and Effect of poor Accounting Records management in Vegetable Oil and associated Industries, southeastern Nigeria. Bayero International Journal of Accounting 2, pp 240-150.

Usama, K. M., \& Yusoff, W. F. (2019). The Impact of Financial Literacy on Business Performance. International Journal of research and Innovation in Social Science, 84-95.

Viffa Consult. (2018). Kenyan SME Financial Survey.

Zada, M., Yukun, C., \& Shagufta, Z. (2019). Effect of Financial Management Practices on the Development of Small to medium size forest enterprises: Insight from Pakistan. GeoJournal.

Publisher's Note: SSBFNET stays neutral with regard to jurisdictional claims in published maps and institutional affiliations.

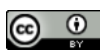

(C) 2021 by the authors. Licensee SSBFNET, Istanbul, Turkey. This article is an open access article distributed under the terms and conditions of the Creative Commons Attribution (CC BY) license (http://creativecommons.org/licenses/by/4.0/).

International Journal of Research in Business and Social Science (2147-4478) by SSBFNET is licensed under a Creative Commons Attribution 4.0 International License. 